University of Nebraska - Lincoln

DigitalCommons@University of Nebraska - Lincoln

USDA Wildlife Services - Staff Publications

U.S. Department of Agriculture: Animal and Plant Health Inspection Service

$1-1-2021$

\title{
Improving evaluation of nonlethal tools for carnivore management and conservation: evaluating fladry to protect an endangered species from a generalist mesocarnivore
}

\author{
R. M. Windell \\ Colorado State University \\ L. L. Bailey \\ Colorado State University \\ J. K. Young \\ USDA APHIS National Wildlife Research Center
}

T. M. Livieri

Prairie Wildlife Research, Colorado

D. A. Eads

Follpwothilssaskdieateditionâteworks at: https://digitalcommons.unl.edu/icwdm_usdanwrc

Part of the Natural Resources and Conservation Commons, Natural Resources Management and

Policy Commons, Other Environmental Sciences Commons, Other Veterinary Medicine Commons, Population Biology Commons, Terrestrial and Aquatic Ecology Commons, Veterinary Infectious Diseases

Commons, Veterinary Microbiology and Immunobiology Commons, Veterinary Preventive Medicine, Epidemiology, and Public Health Commons, and the Zoology Commons

Windell, R. M.; Bailey, L. L.; Young, J. K.; Livieri, T. M.; Eads, D. A.; and Breck, S. W., "Improving evaluation of nonlethal tools for carnivore management and conservation: evaluating fladry to protect an endangered species from a generalist mesocarnivore" (2021). USDA Wildlife Services - Staff Publications. 2504.

https://digitalcommons.unl.edu/icwdm_usdanwrc/2504

This Article is brought to you for free and open access by the U.S. Department of Agriculture: Animal and Plant Health Inspection Service at DigitalCommons@University of Nebraska - Lincoln. It has been accepted for inclusion in USDA Wildlife Services - Staff Publications by an authorized administrator of DigitalCommons@University of Nebraska - Lincoln. 


\section{Authors}

R. M. Windell, L. L. Bailey, J. K. Young, T. M. Livieri, D. A. Eads, and S. W. Breck 


\title{
Improving evaluation of nonlethal tools for carnivore management and conservation: evaluating fladry to protect an endangered species from a generalist mesocarnivore
}

\author{
R. M. Windell ${ }^{1}$ (D) L. L. Bailey ${ }^{1}$, J. K. Young ${ }^{2}$ (D) T. M. Livieri ${ }^{3,4}$, D. A. Eads ${ }^{5}$ \& S. W. Breck ${ }^{1,6}$ \\ 1 Department of Fish, Wildlife, and Conservation Biology, Colorado State University, Fort Collins, CO, USA \\ 2 USDA, National Wildlife Research Center, Predator Research Facility Millville, Logan, UT, USA \\ 3 Prairie Wildlife Research, Wellington, CO, USA \\ 4 Department of Biology, Colorado State University, Fort Collins, CO, USA \\ 5 U.S. Geological Survey, Fort Collins Science Center, Fort Collins, CO, USA \\ 6 USDA, National Wildlife Research Center, Fort Collins, CO, USA
}

\section{Keywords}

Canis latrans; carnivores; coexistence; human-wildlife conflict; camera traps; fladry; endangered species; nonlethal carnivore management.

\section{Correspondence}

Rebecca M. Windell, Home Range Wildlife Research, 33 Eagles Nest Rd, Winthrop, WA 98862, USA.

Email: becca@homerange.org

\section{Present address}

Home Range Wildlife Research, 33 Eagles Nest Rd, Winthrop, WA, 98862, USA

Editor: Vincenzo Penteriani

Associate Editor: Andrés Ordiz

Received 07 December 2020; accepted 30 June 2021

doi:10.1111/acv.12726

\begin{abstract}
Carnivore conservation and management are global research priorities focused on reversing population declines of imperiled species and identifying more effective and humane management of generalist carnivores with thriving populations. Nonlethal methods to mitigate conflict are increasingly used to advance conservation objectives; however, there is limited knowledge about the effectiveness of many nonlethal methods. We tested a nonlethal tool (fladry), that serves as a barrier to deter wolves Canis lupus and coyotes Canis latrans, for its efficacy at preventing coyotes from using prairie dog Cynomys ludovicianus colonies, the primary prey for critically endangered black-footed ferrets Mustela nigripes. We used camera trap data and an occupancy approach to evaluate the tool's efficacy. We measured coyote response to fladry at both a coarse monthly scale (via use, attraction and avoidance probabilities) and a fine scale (via daily activity). Overall, use of areas inside exclosures declined by $60 \%$ after 60 days of fladry application and coyotes avoided some previously used areas both within and outside exclosures. Interestingly, coyotes were attracted to previously unused areas surrounding exclosures and increased activity around the periphery of fladry exclosures by $170 \%$ immediately after fladry installation, suggesting coyotes actively explored these areas and may have responded to fladry in a way that is counterintuitive to management expectations. Occupancy models provided more robust evaluation of fladry and revealed important behavioral responses relative to other common evaluation techniques (i.e. time until first detected crossing). Our results have implications for future development and evaluation of nonlethal tools for carnivore conservation and management globally.
\end{abstract}

\section{Introduction}

Carnivore conservation is increasingly focused on developing strategies that minimize predation threats of carnivores without negatively impacting their populations (van Eeden et al., 2018). This need is critical for endangered carnivores whose conservation requires they coexist with people on shared landscapes (Ripple et al., 2014), and in situations where the expansion of generalist carnivore populations (Arnold et al., 2012; Hody \& Kays, 2018; Drouilly \& O'Riain, 2019) is threatening endangered species, livestock and pets and human health and safety (Allen et al., 2016; Hody et al., 2019; Nattrass, Drouilly \& O'riain, 2020). In both contexts, nonlethal tools are needed that prevent and mitigate predation (Gehring et al., 2006; Shivik, 2006). For example livestock guardian dogs, motion-activated floodlights and fladry are nonlethal tools developed to disrupt, frighten and exclude carnivores from designated areas where conflict might otherwise occur.

Fladry is used as a disruptive stimulus to mitigate wolf Canis lupus predation on livestock (Okarma \& Jedrzejewski, 1997) by taking advantage of wolves' inherent neophobia. 
Fladry consists of a continuous strand of rope with strips of flagging sewn or tied to the rope at $\sim 50 \mathrm{~cm}$ intervals and strung $\sim 50 \mathrm{~cm}$ from the ground. Electrified fladry (i.e. turbo fladry) is a modification that carries an electric charge along the rope. The addition of an electric charge increases fladry effectiveness (Lance et al., 2010) through the addition of an adverse stimulus (i.e. electric shock, Shivik, 2006) and has been used successfully on working ranches (Young et al., $2019 b$ ). Fladry is now used in many parts of the world where nonlethal management of wolves is deemed necessary (e.g. Iliopoulos et al., 2019). Although coyotes Canis latrans have similar neophobic responses to that of wolves (Mettler \& Shivik, 2007), the horizontal spacing of flags on commercial fladry and turbo fladry is likely unsuitable for smallersized coyotes (Davidson-Nelson \& Gehring, 2010). As a result, a recent captive study used the ratio of wolf body width to the horizontal spacing between fladry flags and narrowed the spacing of flags for use with coyotes (Young, Draper \& Breck, 2019a). The study found that modified coyote fladry, when compared with commercial fladry, nearly doubled the duration of effectiveness when used with coyotes (Young et al., 2019a); however, coyote fladry has yet to be tested in a field setting.

In this study, we use coyotes as a model species to demonstrate how nonlethal tools can manage the impacts of expanding mesocarnivore populations on other natural resources, such as endangered species. Coyotes have expanded their range by more than $40 \%$ in the past century (Prugh et al., 2009; Hody \& Kays, 2018) and their recent success has resulted in management challenges similar to those posed by other mesocarnivores (e.g. Gehrt, Riley \& Cypher, 2010; Smith, McDonald \& Wilkinson, 2012; Trouwborst, Krofel \& Linnell, 2015). Coyotes have been identified as problematic in the recovery of imperiled species, where coyote predation can have significant impacts on small, vulnerable populations (Goodrich \& Buskirk, 1995). For example coyotes have contributed to the decline of the endangered San Joaquin kit fox Vulpes macrotis mutica, California least tern Sterna antillarum browni and desert tortoise Xerobates agassizii in California (Butchko, 1990). In addition, coyotes are considered the most important predator of the endangered black-footed ferret Mustela nigripes in prairie ecosystems, where they can cause substantial challenges in reintroduction efforts (Biggins, 2000; Breck et al., 2006). Black-footed ferrets cannot exist without large populations of their primary prey species, prairie dogs Cynomys spp. (Biggins et al., 1993, Biggins, Lockhart \& Godbey, 2006), and have been reintroduced to prairie dog colonies throughout the western USA, where coyotes contribute to $>65 \%$ of predation on reintroduced ferrets (Biggins et al., 2006).

We used an occupancy framework to evaluate the efficacy of a nonlethal tool, turbo coyote fladry (hereafter, fladry), by measuring changes in coyote use, avoidance, attraction and activity of areas sampled by camera traps (Table 1). We tested fladry in a grassland ecosystem where black-tailed prairie $\operatorname{dog}($ C. ludovicianus) colonies are a preferred habitat of coyotes (Krueger, 1986; Ceballos, Pacheco \& List, 1999; Windell, 2019), and used fladry to protect portions of prairie dog colonies identified as critical black-footed ferret habitat. Testing fladry in this setting presented both a unique ecological application for fladry and an environment where variation in biotic and abiotic factors that might influence predator use was relatively easy to measure (e.g. local prairie dog density, proximity to riparian areas, streams and roads).

Our overarching goal was to conduct the first field test of coyote fladry in an ecological context and evaluate fladry's efficacy in terms of use and activity. We had three objectives. First, to determine how fladry affected the probability of coyote use of areas within and directly outside of fladry exclosures. We expected to use within exclosures would abruptly decline with fladry application because coyotes would avoid previously used areas within fladry exclosures and then gradually increase to levels observed prior to installation as they became habituated to fladry (Table 1). Second, to determine how coyote activity changed due to the presence of fladry. We expected fladry would be highly disruptive and decrease coyote activity not only within fladry exclosures but also around the periphery of these areas. Alternatively, coyotes could increase activity around the periphery of fladry exclosures as they investigated the flagging, thus providing insight into the development of behaviors leading to greater conflict (Table 1). Finally, we compared our method of evaluation (i.e. occupancy) to a more common method of evaluating nonlethal tools (i.e. measuring the number of days until first detected crossing) to help evaluate the benefits of using an occupancy approach.

\section{Materials and methods}

\section{Overview}

We conducted our study on black-tailed prairie dog colonies in the northern unit of Badlands National Park (BNP) and the surrounding Buffalo Gap National Grasslands (BGNG) in southwestern South Dakota, USA (Fig. 1; Supporting Information Appendix S1). The study was conducted from August through December 2018 across 5875 ha of black-tailed prairie dog colonies in BNP and BGNG which together comprise the largest population of free-ranging black-footed ferrets ( 115 individuals). Our study used fladry to protect critical black-footed ferret habitat (i.e. high-density prairie dog colonies). We used data from 2017 surveys to identify the largest intact colonies ( $>65 \mathrm{ha}$ ) with medium to high prairie dog density and known ferret presence. We identified seven prairie dog subcomplexes of varying sizes (Agate, Conata West, Heck Table, Lower Sage Creek, Prairie Wind, Sage Creek, Steer Pasture; hereafter, colonies) as our study area (Fig. 1; Table 2). All procedures for studying live animals were approved under USDA-NWRC Animal Care and Use Committee protocol QA-2886.

\section{Fladry experiment}

We modified standard turbo fladry to a narrower flag spacing of $27.9 \mathrm{~cm}$ (Young et al., 2019a) and tested its effectiveness 
Table 1 We tested the efficacy of modified turbo fladry for excluding coyotes Canis latrans from portions of prairie dog Cynomys ludovicianus colonies in South Dakota, USA from August to December 2018

\begin{tabular}{|c|c|c|c|c|}
\hline Response & Parameter & Scale & Definition & Prediction of treatment responses \\
\hline$\overline{\text { Use }}$ & Occupancy $(\Psi)$ & Coarse & $\begin{array}{l}\text { The probability a unit is used by } \\
\text { coyotes }\end{array}$ & Decreased use during fladry application \\
\hline Avoidance & Extinction $(\epsilon)$ & Coarse & $\begin{array}{l}\text { The probability that a unit used in } \\
\text { the previous season becomes } \\
\text { unused }\end{array}$ & $\begin{array}{l}\text { Evidence of avoidance inside fladry exclosures during first } \\
30 \text { days of application as barrier repels coyotes }\end{array}$ \\
\hline Attraction & Colonization $(\gamma)$ & Coarse & $\begin{array}{l}\text { The probability that a unit unused in } \\
\text { the previous season becomes used }\end{array}$ & $\begin{array}{l}\text { Evidence of attraction inside fladry exclosures during second } \\
30 \text { days of application as coyotes learn to overcome barrier }\end{array}$ \\
\hline Activity & Detection $(p)$ & Fine & $\begin{array}{l}\text { The probability coyotes were } \\
\text { detected during a survey at a used } \\
\text { unit }\end{array}$ & $\begin{array}{l}\text { (1) Decreased activity both inside and outside fladry exclosures } \\
\text { during first } 30 \text { days of application; high avoidance } \\
\text { (2) Decreased activity inside fladry and increased activity outside } \\
\text { fladry during first } 30 \text { days of application; attraction to barrier }\end{array}$ \\
\hline
\end{tabular}

Occupancy parameters were defined with respect to coyote response to fladry treatments. For each response term, we provide the associated occupancy parameter, its temporal scale, the definition of the parameter as it applies to our study, and our expected response. Coarse temporal scale estimates provide information during or between seasons (i.e. predefined 30-day periods) and fine temporal scale estimates provide information at a daily scale (i.e. the length of each survey).

at excluding coyotes from areas within fladry exclosures on each treatment colony (Fig. 1). To test the effectiveness of this tool, we used a randomized before-after-control-impact design within an occupancy framework. We focused our experiment in autumn because this is a critical period when ferrets, in particular kits emerging for the first time, are very vulnerable to predation and the use of temporary protection from coyotes could greatly enhance the conservation of this species (Breck et al., 2006; Matchett, Breck \& Callon, 2013). We randomized the assignment of control $(n=2)$ and treatment $(n=5)$ colonies (Table 2) using an unbalanced design (Shaffer \& Johnson, 2008). Resident coyotes are territorial and utilize distinct home ranges, where areas they use more than $50 \%$ of the time are defined as core use areas (Schroeder, 2007). To minimize the chance of individual coyotes visiting more than one exclosure, all fladry treatments were separated by $\geq 1.5 \mathrm{~km}$, the diameter of coyote core use areas in BNP and BGNP (Schroeder, 2007). Each of our five treatment colonies (where fladry exclosures were installed) enclosed 8 ha of prairie dog colony habitat (i.e. approximate size of female ferret core use area; Livieri \& Anderson, 2012) and control colonies received no fladry for protection. All colonies were monitored using an array wildlife camera traps. Camera arrays and exclosures were placed near the center of each selected colony, where prairie dog density was observed to be highest (Fig. 1).

We used camera traps to collect coyote detection data and divided our prairie dog colonies into two strata. Our first stratum comprised the area inside the fladry exclosure and the second stratum was delineated as a $100-\mathrm{m}$ buffer surrounding the exclosure (Fig. 1). Four cameras were placed in each stratum, yielding a total of 20 cameras per stratum on our five treatment colonies and eight cameras per stratum on our two control colonies (total of 56 cameras; Fig. 1). Although control colonies lacked exclosures, we installed cameras in the same arrangement. Sample units (hereafter, units) were defined as the effective area sampled by each camera. Based on an average camera detection range of $30 \mathrm{~m}$ and a 45-degree field of view (Trailcampro.com, Springfield, MO), the effective area sampled by each camera was $\sim 0.28$ ha, or about $1 / 8$ of the area within exclosures. As a result, each unit was considered independent; a coyote could easily use an area within or outside the exclosures and never have a chance of being detected by one of our cameras. Not assuming independence of our camera units would violate an important assumption of the occupancy analysis; namely, if a unit is used during a season, there is a nonzero chance of detecting that occurrence in a given survey (MacKenzie et al., 2017).

We used active prairie dog burrows as focal points to increase coyote detection. All cameras were placed on tposts, approximately $50 \mathrm{~cm}$ from ground level and $7.5 \mathrm{~m}$ from the center of the nearest active prairie dog burrow opening. To maximize interspersion, cameras inside the exclosure stratum were placed in each corner of the exclosure and pointed towards the center of the protected area. Cameras along the buffer stratum were systematically placed at equal intervals, from a random starting point, along the $100-\mathrm{m}$ stratum buffer line and pointed at the nearest active burrow from a randomly selected cardinal azimuth (i.e. N, S, $\mathrm{E}, \mathrm{W})$.

We set up camera stations a minimum of 30 days prior to the trials to allow coyotes to condition to their presence. Following the conditioning period, we set cameras on all seven colonies and collected 30 days of detection data before fladry exclosures were installed. Following pre-fladry data collection, we constructed fladry exclosures on each treatment colony (Fig. 1). Fladry exclosures were established between 8 September 2018 and 2 October 2018, and were timed to be installed with the removal of livestock (i.e. cattle or bison) from United States Forest Service (USFS) grazing allotments (Table 2). Fladry exclosures were established for 56-60 days (Table 2) and checked every 7-10 days to fix damaged lines due to weather or other disturbance and service cameras. Control sites did not require extensive maintenance and were 


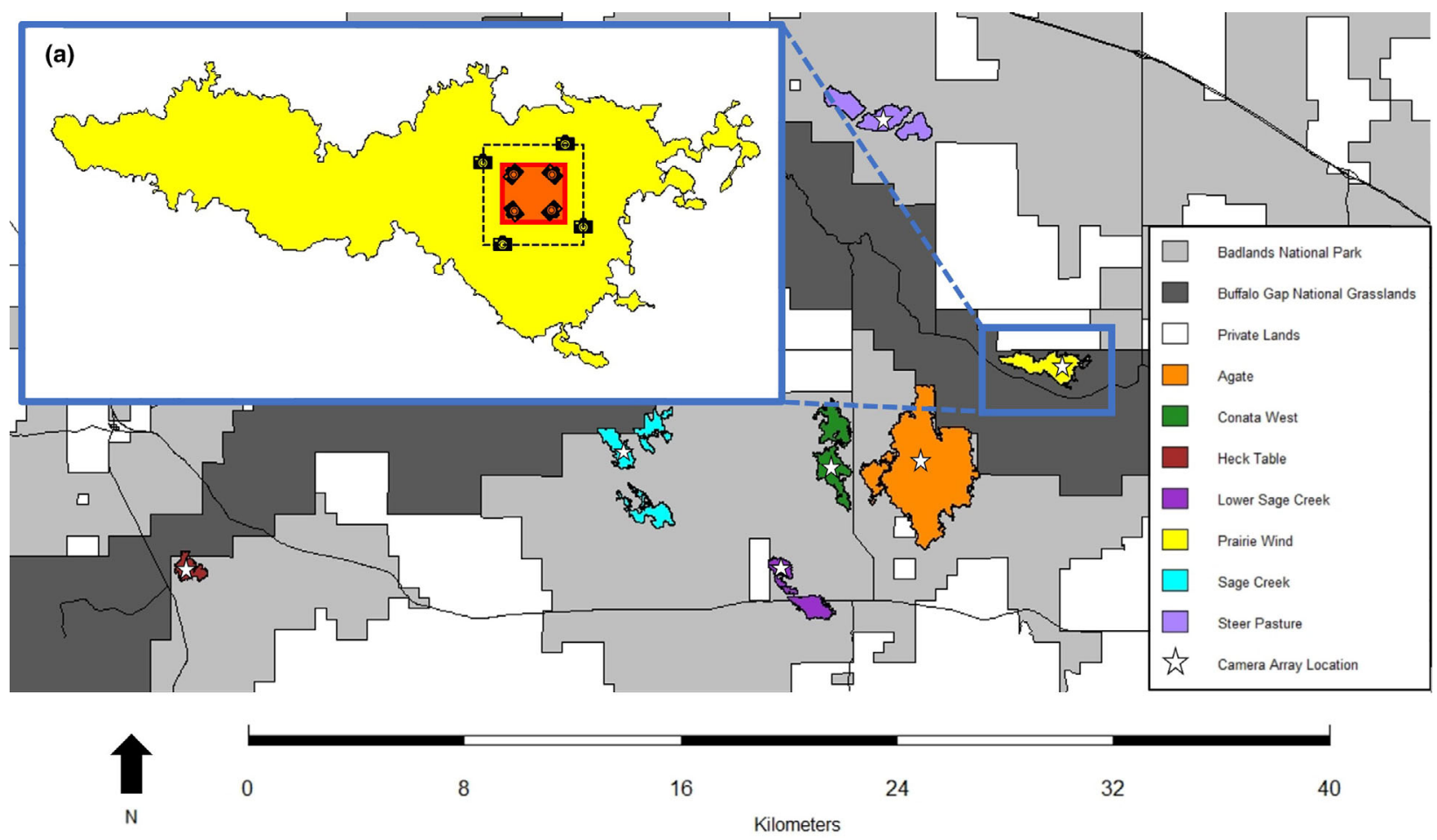

Figure 1 We tested the efficacy of modified turbo fladry for excluding coyotes Canis latrans from portions of prairie dog Cynomys ludovicianus colonies in South Dakota, USA from August to December 2018. Four wildlife cameras traps were deployed in the same pattern across each of two stratum on both control and treatment prairie dog colonies (colored polygons) used in our study (see Table 2 for more details about each colony). Square fladry exclosures (red line, panel a) protected approximately 8 ha of prairie dog colony habitat. The light red area within fladry exclosures formed the first stratum (fladry strata) and a $100 \mathrm{~m}$ buffer line (black dashed) surrounding the exclosure formed the second stratum (buffer strata; see the Fladry experiment subsection in Methods for details on camera placement). White stars on each prairie dog colony indicate the location of the camera array. White spaces between Badlands National Park (dark grey polygon) and Buffalo Gap National Grasslands (light grey polygon) represent privately held lands.

visited 1-2 times over the course of the study to service cameras.

\section{Camera and covariate data}

Three different brands of cameras traps were used in our study: Browning BTC Series $(n=24)$, Bushnell Trophy Series $(n=21)$ and Cuddeback Longrange IR $(n=11)$ and we systematically placed brands to ensure they were interspersed evenly among areas and strata within areas. While we programmed cameras similarly, camera brands are known to have variable detection ranges, fields of view and sensitivity (Meek, Ballard \& Fleming, 2015), thus we included camera brand as a covariate on detection probability in all models (see Modeling approach below).

Camera data were processed using the Colorado Parks and Wildlife Photo Warehouse software (Ivan \& Newkirk, 2016), where each photo of an animal was identified to species by two independent observers. We used raw camera data to evaluate the date of the first detection within each fladry exclosure and considered coyote detection events at each camera to be independent if detections were $>1 \mathrm{~h}$ apart
(Lewis et al., 2015; Lendrum, Crooks \& Wittemyer, 2017). We censored data from any periods in which cameras malfunctioned (e.g. dead batteries, camera knocked down by cattle) and calculated the number of functional camera trap days per camera site.

We hypothesized four variables could influence coyote use in our study area: distance to nearest riparian area; distance to nearest two-track road; distance to nearest stream or gully; and local prairie dog density. Riparian areas could provide cover, water and den sites across the otherwise open and relatively unprotected grasslands. Two-track roads are ungraded vehicle paths that have been driven enough to wear distinct tire tracks and could serve as travel corridors for coyotes. Streams and gullies could serve multiple purposes, including areas of cover, water sources, den sites and travel corridors. We expected that as distance to each of these three variables decreased, coyote use would increase. We acquired shapefiles of riparian areas (including lakes and ponds), two-track roads, streams and gullies from the USDA Data Gateway and used ArcMap (Esri, Redlands, CA, USA) and measured the nearest distance $(\mathrm{m})$ to each of these features from our camera units. 
Table 2 We tested the efficacy of modified turbo fladry for excluding coyotes Canis latrans from portions of prairie dog Cynomys ludovicianus colonies in South Dakota, USA from August to December 2018

\begin{tabular}{lllllll}
\hline Colony & Treatment & Size (ha) & Pre-fladry start & Fladry start & Fladry breakdown & Days to 1st crossing \\
\hline Agate & Fladry & 1518 & $8 / 9 / 2018$ & $9 / 8 / 2018$ & $11 / 7 / 2018$ & 9 \\
Heck table & Fladry & 131 & $9 / 2 / 2018$ & $10 / 2 / 2018$ & $12 / 1 / 2018$ & 23 \\
Lower sage creek & Fladry & 235 & $8 / 16 / 2018$ & $9 / 15 / 2018$ & $11 / 10 / 2018$ & $\Theta_{1}$ \\
Prairie wind & Fladry & 234 & $8 / 9 / 2018$ & $9 / 8 / 2018$ & $11 / 7 / 2018$ & UKN \\
Steer pasture & Fladry & 340 & $8 / 30 / 2019$ & $9 / 29 / 2018$ & $11 / 28 / 2018$ & $\Theta_{2}$ \\
Conata west & Control & 359 & $8 / 11 / 2018$ & $9 / 10 / 2018$ & $11 / 9 / 2018$ & 17 \\
Sage creek & Control & 325 & $9 / 1 / 2018$ & $10 / 1 / 2018$ & $11 / 30 / 2018$ & 11 \\
\hline
\end{tabular}

We used seven prairie dog colonies in our study, each of which received a random treatment assignment and varied in size, operational dates and raw number of days until first coyote detection within a fladry exclosure. We installed cameras 30 days prior (Pre-Fladry Start) to installing fladry exclosures (Fladry Start) and removed exclosures after 60 days (Fladry Breakdown). For control colonies no fladry exclosures were installed and the dates listed in the Pre-Fladry Start, Fladry Start and Fladry Breakdown columns represent corresponding time periods for which we monitored change in coyote use in our occupancy analysis. The number listed in the Days to 1st Crossing column for control colonies reflects the first coyote detection within the fladry strata (see Fig. 1). The average day of first crossing was 37 days after installation ( $n=4, S E=12$ days). Date to first crossing was not available (UKN) for our exclosure on the Prairie Wind colony due to a windstorm (see the Modeling coyote use dynamics subsection in Methods for details on windstorm). For Lower Sage Creek $\left(\Theta_{1}\right.$; total trial days $\left.=56\right)$ and Steer Pasture $\left(\Theta_{2}\right.$; total trial days $\left.=60\right)$ colonies, coyotes were never detected within exclosures.

We measured local prairie dog density by counting all burrows within a 30-m buffer of each camera, classifying each burrow as active or inactive. Burrows were considered active based on the same criteria used to select active burrows for cameras placement (Biggins et al., 1993). We used the linear relationship Biggins et al. (1993) reported between black-tailed prairie dog active burrow counts and individual animals to estimate prairie dog density. We used a Welch two-sample $t$-test to explore differences in prairie dog density between control and treatment colonies and between stratum inside and outside fladry exclosures and found no differences (Supporting Information Appendix S2). We tested for correlation between our four habitat covariates using Pearson's product-moment correlation test and retained all covariates in our analysis as none of the correlations exceeded 0.70 (I $r \mid<0.70$, Dormann et al., 2013).

\section{Measuring coyote use}

Occupancy studies can use models that provide both fineand coarse-scale measurements of a species' behavioral response (Table 1). We evaluated coyote use within and surrounding fladry exclosures using camera trap detection data and a dynamic (i.e. multi-season) occupancy framework (MacKenzie et al., 2017). We define occupancy (i.e. $\Psi$ ) as the probability each unit is used by a coyote during a predefined season. Dynamic occupancy models provide a means to assess changes in coyote use over multiple seasons (e.g. before and after the application of a nonlethal tool) via two dynamic parameters; 'extinction' probability (i.e. $\epsilon$; the probability that a unit used in the previous season is not used in the current season) and 'colonization' probability (i.e.; $\gamma$; the probability that a previously unused unit in one season is used in the subsequent season; MacKenzie et al., 2017). These parameters are coarse-scale measurements of the species' avoidance $(\epsilon)$ or attraction $(\gamma)$ to areas in response to the presence of a disruptive stimuli, such as fladry (Table 1). Finally, detection probability $(p)$ accounts for the likely possibility that a species may use an area during a season, but not be detected on a given survey. Detection probability can also be interpreted as the frequency of use and differentiates areas that are used often relative to those that may only be used occasionally during a season (i.e. fine temporal-scale use). When modeled with covariates, detection probability can reflect differences in relative use, local abundance, and/ or the behavioral response of animals (Royle \& Nichols, 2003; Royle et al., 2005; Sollmann et al., 2013; Lewis et al., 2015). While measures of abundance and behavioral variation are combined in our estimates of detection probability, for the purposes of this study, we consider detection probability a relative measure of coyote activity (Table 1 ).

Initial pre-fladry use, avoidance and attraction probabilities (Table 1) were modeled to estimate changes in coyote use in both strata (inside and outside fladry exclosures) over three 30-day seasons, for both treatment and control units. Each season consisted of 30 surveys (i.e. $24 \mathrm{~h}$ periods split at noon to capture the more crepuscular and nocturnal activity of coyotes; Andelt \& Gipson, 1979; Kitchen, Gese \& Schauster, 2000; Windell, 2019), where the first season measured coyote use and activity prior to fladry installation, and the second and third seasons measured coyote use and activity after fladry installation. We censored nine surveys from our detection histories for units on the Prairie Wind colony due to a windstorm with $55+\mathrm{mph}$ gusts that compromised the exclosure's structure. We also omitted the first crossing data for the Prairie Wind exclosure (Table 2); the first detection inside Prairie Wind occurred the day after the windstorm and likely did not reflect an actual crossing event.

The number of days until first crossing is presented separately from the occupancy framework. First crossing metrics are presented at the colony level and detail how long each fladry exclosure excluded coyotes. 


\section{Modeling approach}

Given our occupancy models included many parameters (Table 1), we used a hierarchical approach to model a series of interconnected hypotheses (Fig. 2). Our initial model structure included interactions between stratum (str) and treatment (trt) on all model parameters (e.g. $\Psi(\operatorname{str} \times \operatorname{trt}))$ including probabilities of use $(\Psi)$, avoidance $(\epsilon)$, attraction $(\gamma)$ and activity $(p)$ probabilities for our three seasons. Additionally, we included seasonal (seas) variation in avoidance $(\epsilon(\operatorname{str} \times \operatorname{trt} \times$ seas $))$ and attraction probabilities $(\gamma(\operatorname{str} \times \operatorname{trt} \times$ seas)) and a linear temporal trend in coyote activity following fladry installation $\left(p_{1} \quad(\operatorname{str} \times \operatorname{trt}), p_{2}(\operatorname{str} \times \operatorname{trt} \times \mathrm{T}), \quad p_{3}\right.$ $(\operatorname{str} \times \operatorname{trt} \times \mathrm{T}))$.

Using this initial model structure, we first investigated the effect of camera brand on detection (i.e. nuisance variation in our ability to detect coyotes; Supporting Information Appendix S3). Next, we modeled the effects of our habitat covariates on coyote use and tested for inherent variation in use between strata and treatments prior to fladry installation at treatment colonies $(\Psi$, Supporting Information Appendix S4). We then constructed a set of models to address specific hypotheses related to avoidance probability $(\epsilon)$ and attraction probability ( $\gamma$; Fig. 2, Supporting Information Appendix S5 and S6). Our a priori expectation was that coyotes would use camera units in control areas similarly throughout the study and exhibit no avoidance behavior between seasons and avoid previously used camera units inside exclosures immediately after fladry installation $\left(\epsilon_{1}\right)$. We tested similar structures for the probability of attraction (Fig. 2, Step 4; Supporting Information Appendix S6). Here, we expected that coyotes would exhibit no attraction to units on control colonies between seasons but, in contrast, would be attracted to units inside fladry exclosures during season $3\left(\gamma_{2}\right)$, after they learned to overcome the fladry barrier.

Finally, we tested for variation in coyote activity associated or not associated with our fladry treatment (Fig 2, Step 5; Supporting Information Appendix S7). We expected similar activity at used camera units not influenced by fladry (i.e. coyote activity during the pre-fladry season and at control sites). We refer to this as our 'reference' activity level which serves as a comparison for our hypothesized responses at treatment units in the two stratum and across the second $(p 2)$ and third ( $p 3)$ seasons when fladry had been deployed. We hypothesized that coyote activity at treatment units could: (1) decline linearly (trend, T) across surveys in both the second and third seasons, (2) decline linearly during second season followed by a plateau $(\mathrm{P})$ during our third season and (3) remain constant (.), representing no change in coyote activity at used camera units during both the second and third seasons (Fig. 2).

We used Program MARK (White \& Burnham, 1999) to conduct all occupancy analyses. We used $\mathrm{AIC}_{c}$ model selection (Burnham \& Anderson, 2002) to identify the top model in each step from a limited set of a priori hypotheses (Fig. 2). The best supported model structures were those with the lowest $\mathrm{AIC}_{c}$ values and no uninformative parameters (Arnold, 2010; Leroux, 2019).

\section{Results}

\section{Camera and covariate data}

Cameras were functional for 4444 trap nights across 56 camera units, where the average number of functional days was 26.2 days, 26.6 days and 25.0 days for first, second and third seasons, respectively. Coyotes were detected at 30 of our 56 units over the course of our study: 22 units in season 1; 18 units in season 2; and 15 units in season 3. Detections at the units ranged from 1 to 4 days (i.e. surveys) in seasons 1 and 3 and 1-7 days in season 2. As expected, the number of days until first coyote detection within a fladry exclosure was highly variable $(\bar{x}=37+$ days, $\mathrm{SE}=12$ days, range $=-$ 9-60 days, $n=4$; Table 2).

\section{Dynamic occupancy analysis}

Camera brand strongly influenced detection probability, with Browning cameras having a higher detection probability than our other two camera brands, Bushnell and Cuddeback (effect size on the logit scale: $\hat{\beta}=1.44,95 \%$ CI $[0.92$, 1.96]; Supporting Information Appendix S3). We retained this camera covariate in all models and report estimated detection probabilities for those units sampled with Browning cameras. We found little or no effect of habitat covariates on initial coyote use (Supporting Information Appendix S4).

The initial, pre-fladry use of prairie dog colonies by coyotes during the first of our 30-day seasons (season one) was high $\left(\hat{\Psi}_{1}=0.80,95 \%\right.$ CI $\left.[0.56,0.93]\right)$ across our entire study area but declined within exclosures after fladry application during season $2\left(\hat{\Psi}_{2}=0.50,95 \%\right.$ CI $\left.[0.29,0.72]\right)$ and further declined during season $3\left(\hat{\Psi}_{3}=0.32,95 \%\right.$ CI $[0.07$, 0.57]; Fig. 3). When compared to control units, coyotes used units inside fladry exclosures $37 \%$ and $60 \%$ less during the second and third seasons, respectively. Coyote use also declined slightly outside fladry exclosures, where coyotes used units $12 \%$ and $8 \%$ less during the second and third seasons, respectively. As expected, coyote use and activity did not change over the three seasons at our control units (Supporting Information Appendix S5-S7). In contrast, we found evidence that coyotes avoided previously used units after fladry installation $(\hat{\varepsilon}=0.37,95 \%$ CI $[0.17,0.63]$; Supporting Information Appendix S5) but were attracted to previously unused units outside the fladry exclosure $(\hat{\gamma}=1.00$, Supporting Information Appendix S6).

Coyote activity was similar across all control and treatment units during the first season and remained at this same level at control units throughout the study (Supporting Information Appendix S7). We used this 'reference' activity level to compare to changes in activity at treatment units using our final set of seven candidate models (Table 3; Fig. 4). Several models in this final set had similar support (i.e. within $\sim \Delta 2$ AIC and held $9 \%-26 \%$ of the model weight); however, each model representing a hypothesized response to fladry was better supported than the model with no 


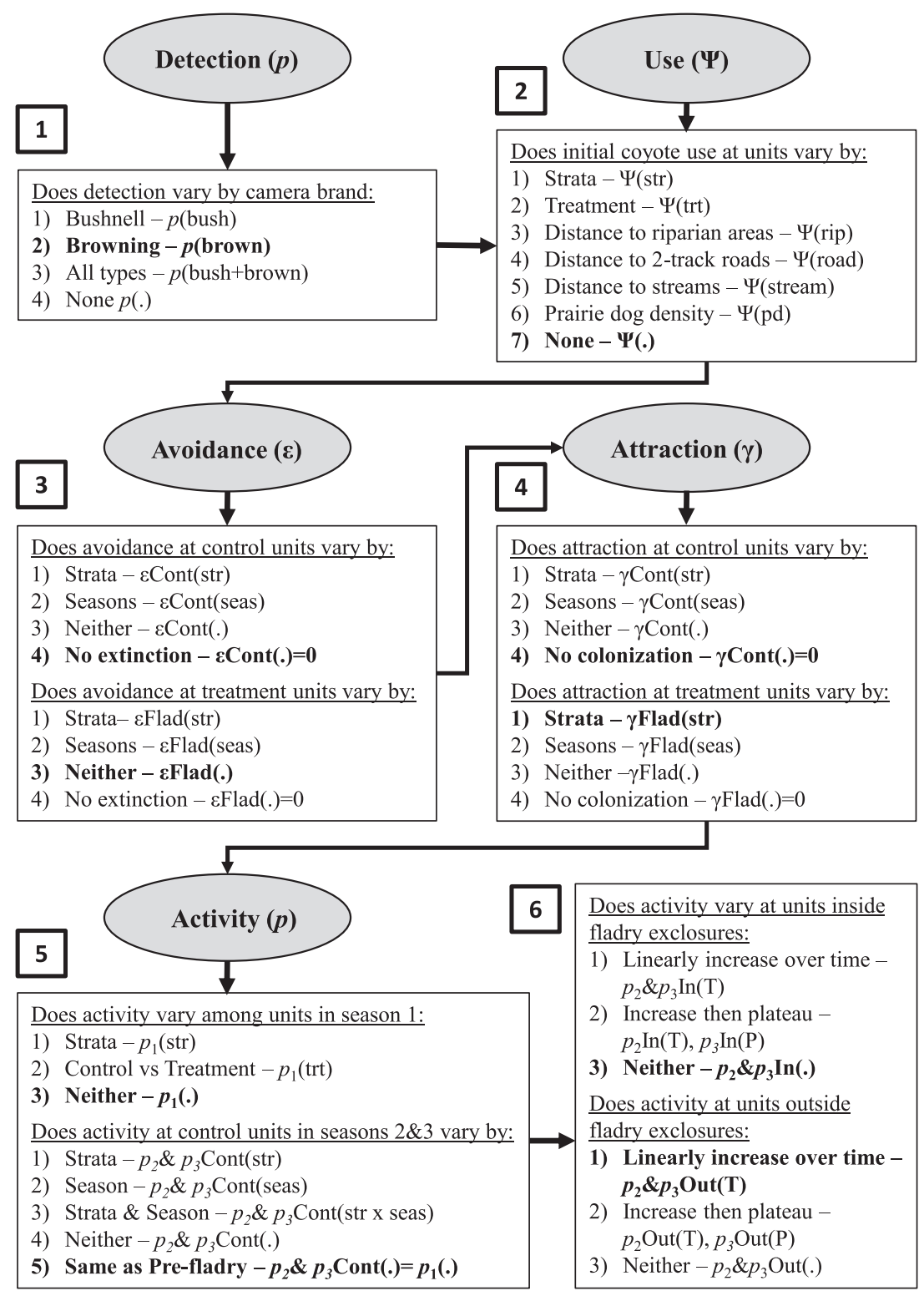

Figure 2 We tested the efficacy of modified turbo fladry for excluding coyotes Canis latrans from portions of prairie dog Cynomys ludovicianus colonies in South Dakota, USA from August to December 2018. We used an occupancy framework and hierarchical approach to model selection to evaluate changes in coyote use, avoidance, attraction and activity at camera units in response to fladry. In each step, we asked a specific question (underlined text) and carried the best supported structure (in bold) forward to the next step. We first modeled nuisance detection variation due to camera brand (1), followed by coyote use (2) and then avoidance (3) and attraction (4) at control (Cont) and treatment (Flad) units. In our final two steps, we developed a reference level of activity from data prior to fladry installation (season 1) across all units and at control units in all seasons (5) before asking specific questions in regard to change in coyote activity at units inside (In) and outside (Out) fladry exclosures (6).

difference in coyote activity in response to fladry (Table 3). Furthermore, models consistently described a decreased level of activity inside fladry and increased level of activity outside fladry. We found that coyote activity at units within the exclosure declined after fladry installation and remained at this lower level for the duration of the fladry experiment $(\hat{p}=0.03,95 \%$ CI $[0.01,0.06]$; Fig. 4$)$. Prior to fladry installation, coyotes used approximately $80 \%$ of the units, $1-$
2 days per month, whereas post-fladry installation, coyote use of units within exclosures dropped to $32 \%-50 \%$ and they frequented those areas $<1$ day per month (Table 3, Figs 3 and 4$)$. Outside fladry, we found that coyote activity initially increased $(\hat{p}=0.14,95 \%$ CI $[0.08,0.24])$ following fladry installation, before decreasing over the course of the next 60 days to activity levels similar to the reference level after $\sim 50$ days of application (Table 3, Fig. 4). 


\section{Discussion}

Our study represents the first experimental field test and ecological application of fladry on coyotes and demonstrated that fladry excluded coyotes from protected areas for an average of 37 days ( $\mathrm{SE}=12$ days). The benefit of decreased coyote use in protected areas was contrasted by increased coyote use outside the protected area. This could be important if the protected resource (e.g. black-footed ferrets) could travel outside the protected area. This highlights the importance of utilizing monitoring techniques that can provide deeper insight into the behavioral reaction of the mesocarnivore being managed.

We used a dynamic occupancy approach to assess fladry efficacy beyond the number of days the tool was effective and found that fladry decreased coyote spatial and temporal use within protected areas. Measures of use, avoidance and attraction provided information about which units coyotes used and how to use changed in response to fladry, both inside and outside fladry exclosures, at a coarse temporal scale (i.e. over a 30-day season; Table 1). Relative to control units, coyote use of protected areas within fladry exclosures was reduced across both post-installation seasons. Use inside fladry exclosures decreased during the first 30 days of our experiment, and surprisingly, further decreased another $23 \%$ during the final 30 days (Fig. 3), suggesting that it may be beneficial to install fladry in advance of a critical protection period. Estimates of avoidance further supported declined use of protected areas, although the probability of coyotes avoiding a unit was equal across strata and seasons on treatment colonies (i.e. $\hat{\varepsilon}=0.37$ ). More interestingly, the patterns underlying attraction varied substantially inside and outside of fladry exclosures. Inside fladry exclosures coyote attraction was zero (i.e. $\hat{\gamma}=0.00$ ), suggesting that when coyotes

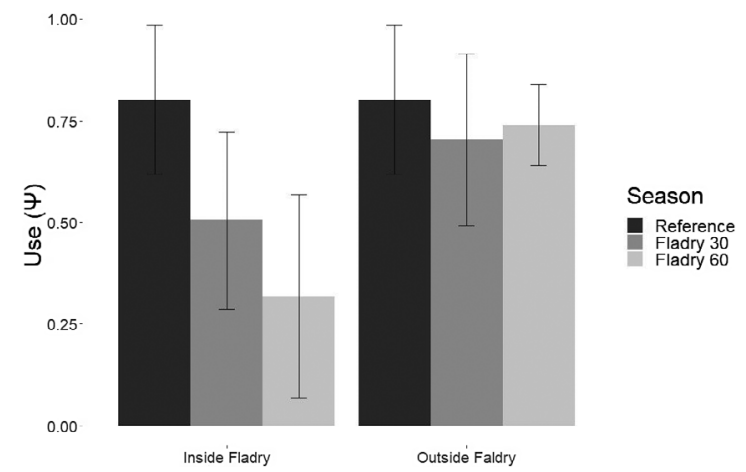

Figure 3 We tested the efficacy of modified turbo fladry for excluding coyotes Canis latrans from portions of prairie dog Cynomys ludovicianus colonies in South Dakota, USA from August to December 2018. Coyote uses probabilities $(\Psi)$ and associated 95\% confidence intervals were derived for camera units on treatment colonies inside fladry exclosures (Inside Fladry) and outside fladry exclosures (Outside Fladry) during each season: pre-fladry (Reference) and two post-installation seasons representing the first 30 days of fladry application (Fladry 30 ) and second 30 days of fladry application (Fladry 60). did enter fladry exclosures, they only used those areas used prior to fladry installation. Conversely, we observed a very different pattern outside fladry exclosures in which attraction to previously unused areas was high (i.e. $\hat{\gamma}=1.00$ ). This implies that even though we found coyotes avoided a subset of previously used units outside fladry exclosures (i.e. as described by our avoidance estimate), coyotes also explored previously unused areas surrounding the exclosure. However, when interpreting these results, it is important to consider that initial coyote use of prairie dog colonies was generally high (i.e. $\hat{\Psi}_{1}=0.80$ ).

Our estimates of coyote activity yielded information about how coyotes interacted with fladry at a fine temporal scale (Table 1). Although the 95\% confidence intervals between estimates of activity during reference/pre-fladry time periods and post-fladry time period overlapped (Fig. 4), we believe our results support a biological impact of fladry on coyote activity. In the post-fladry installation period, coyote activity within exclosures declined by $47 \%$ and remained lower than reference levels for the duration of our fladry experiment (Fig. 4). Outside fladry exclosures, we observed a different pattern, where activity initially increased by more than $170 \%$ after fladry installation before gradually declining to

Table 3 We tested the efficacy of modified turbo fladry for excluding coyotes Canis latrans from portions of prairie dog colonies in South Dakota, USA from August to December 2018

\begin{tabular}{|c|c|c|c|c|c|}
\hline Model & $\mathrm{AlC}_{\mathrm{c}}$ & $\Delta \mathrm{AlC}_{\mathrm{C}}$ & $w_{i}$ & $\begin{array}{l}-2 \log \\
(L)\end{array}$ & $K$ \\
\hline$\overline{p_{2} \& p_{3} \ln (.), p_{2} \& p_{3} \operatorname{Out}(\mathrm{T})}$ & 879.70 & 0 & 0.27 & 860.55 & $\overline{9}$ \\
\hline $\begin{array}{l}p_{2} \& p_{3} \ln (.), p_{2} \& p_{3} \text { Out } \\
(\text { seas } \times T)\end{array}$ & 880.30 & 0.60 & 0.20 & 856.59 & 11 \\
\hline $\begin{array}{l}p_{2} \ln (T), p_{3} \ln (P), p_{2} \& p_{3} \text { Out } \\
(\text { seas } \times T)\end{array}$ & 880.72 & 1.01 & 0.16 & 854.68 & 12 \\
\hline $\begin{array}{l}p_{2} \& p_{3} \ln (.), p_{2} \text { Out }(T), p_{3} \text { Out } \\
(\mathrm{P})\end{array}$ & 881.04 & 1.33 & 0.14 & 861.88 & 9 \\
\hline$p_{2} \& p_{3} \ln (),. p_{2} \& p_{3}$ Out(.) & 881.59 & 1.88 & 0.10 & 864.67 & 8 \\
\hline $\begin{array}{l}p_{2} \& p_{3} \ln (T), p_{2} \& p_{3} \text { Out } \\
(\text { seas } \times T)\end{array}$ & 881.84 & 2.13 & 0.09 & 855.80 & 12 \\
\hline$p_{2} \& p_{3}$ Flad $($ str $\times$ seas $\times T)$ & 885.09 & 5.38 & 0.02 & 854.31 & 14 \\
\hline
\end{tabular}

We modeled activity across the first $\left(p_{2}\right)$ and second $\left(p_{3}\right) 30$ days of our fladry experiment both inside (In) and outside (Out) fladry exclosure stratum (Str) at treatment camera units to test three hypothesized responses. These structures include: (1) a constant (.) activity level (no change); (2) a time trend ( $\mathrm{T}$ ) in activity across all 60 days of our experiment $\left(p_{2} \& p_{3} S \operatorname{St}(T)\right)$; and (3) a time trend in activity during the first 30 days of fladry application, followed a plateau $(\mathrm{P})$ in activity in the second 30 days $\left(p_{2} \operatorname{Str}(\mathrm{T}), p_{3} \operatorname{Str}(\mathrm{P})\right)$. We used a general structure, $p_{2} \& p_{3}$ Out(seas $\left.\times T\right)$, to first test our hypotheses for activity within the exclosures and retained the bestsupported structure to then test our hypotheses for activity at units outside fladry exclosures. See the Dynamic occupancy analysis subsection in Results for parameter structures supported in the previous steps of the analysis. Model selection statistics include: $\mathrm{AIC}_{c}=$ Akaike's Information Criterion adjusted for small sample bias; $w_{i}=\mathrm{AIC}_{c}$ model weights; $-2 \mathrm{Log}(L)=$ negative log likelihood; $K=$ number of model parameters. 


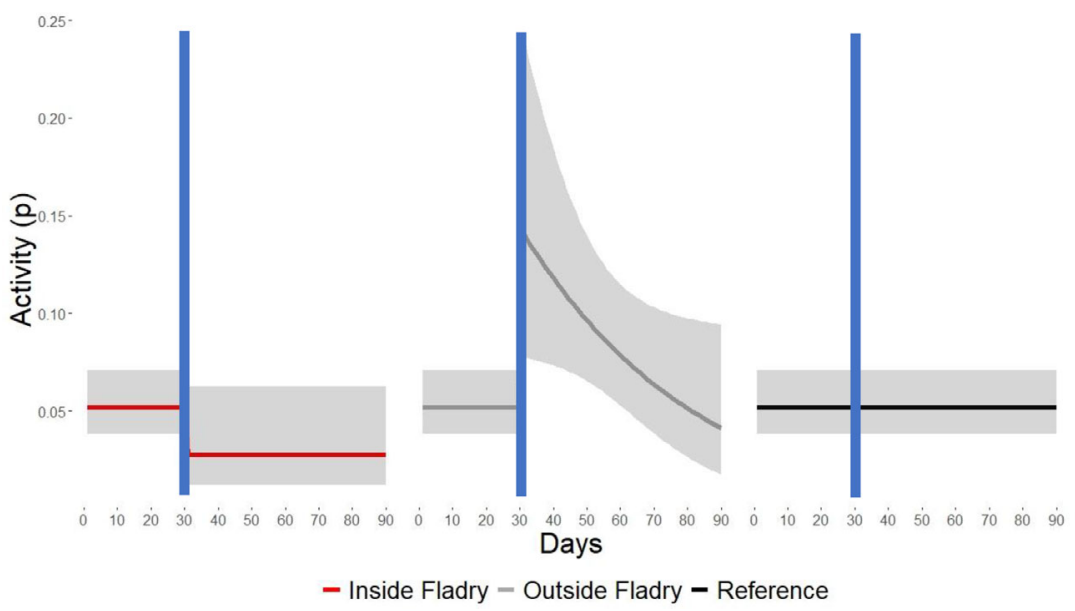

Figure 4 We tested the efficacy of modified turbo fladry for excluding coyotes Canis latrans from portions of prairie dog Cynomys ludovicianus colonies in South Dakota, USA from August to December 2018. Daily coyote activity, with associated 95\% confidence intervals, varied at units inside fladry exclosures (Inside Fladry; red), outside fladry exclosures (Outside Fladry; grey) and at control units (Reference; black). The first 30 days (Days 1-30; before blue vertical bar) reflect detection probability prior to fladry installation across all units. The following 60 days (Days 31-90; after blue vertical bar) reflect changes in activity in response to fladry. Estimates are obtained from the bestsupported coyote activity model, $p_{2} \& p_{3} \ln (),. p_{2} \& p_{3} \mathrm{Out}(\mathrm{T})$.

reference level after $\sim 50$ days of application. This change in activity provides evidence that coyotes, either at the individual or population level, actively explored fladry, where changes in daily activity at units can be attributed to either variation in local coyote abundance or the behavioral response of coyotes. For example canids employ investigative behaviors as they learn to overcome nonlethal prevention measures (Much et al., 2018) and investigation of fladry may inherently increase an individual's spatial or temporal activity (Sih, Bell \& Johnson, 2004; Réale et al., 2007). As a result, increased activity around the outside of our fladry exclosures may have documented the behavior of an individual or individuals learning to overcome fladry (e.g. Young, Mahe \& Breck, 2015).

The initial increase in use outside fladry exclosures indicates coyotes may have been attracted to the vicinity of exclosures to assess fladry risk (i.e. risk-assessment, predator inspection; Lima \& Dill, 1990; Frid \& Dill, 2002), where coarse-scale measures of attraction and avoidance provide information about the riskassessment process over time (Table 1). Alternatively, fladry may have created a barrier for which activity that normally would have occurred within exclosures was displaced to the periphery of exclosures, therefore resulting in higher detection of coyotes at these locations. This could have resulted because exclosures removed 8 hectares of an average 1430-1520 ha coyote home range (Schroeder, 2007), accounting for a $0.56 \%$ $0.53 \%$ reduction in home range size. Given the emerging importance in understanding how behavior influences conflict (Blackwell et al., 2016; Breck et al., 2019; Greggor, Berger-Tal \& Blumstein, 2020), future studies could better understand intraspecific variation and development of these behaviors by supplementing occupancy data with movement data from marked or telemetered individuals.
Our study used fladry to protect small, high-density portions of prairie dog colonies occupied by endangered blackfooted ferrets and decreased coyote use of these areas. Due to inherent challenges associated with monitoring the survival and movements of black-footed ferrets (e.g. small sample sizes, fossorial activity, difficulties affixing transmitters), we could not provide definitive evidence for how coyote exclusion influenced ferret populations, nor is it clear if excluding coyotes from larger areas (i.e. entire prairie dog colonies) provided additional protection to ferrets or increased coyote motivation to enter exclosures. Related to these questions is the need for increased understanding about how coyote motivation to access wild prey translates to domestic livestock scenarios and vice versa, similar to past studies with wolves (e.g. Musiani et al., 2003). Testing the efficacy of coyote fladry for protecting livestock is an important next step for robust evaluation of this nonlethal tool because coyotes are the primary predator of livestock in the U.S. (USDA APHIS, $2015 a, b)$.

We encourage future nonlethal tool studies to employ an occupancy framework to quantify the behavioral response of carnivores to a given tool. Occupancy studies provide a simple structure to rigorously estimate multiple dynamic parameters such as use, avoidance, attraction and activity. This, coupled with their ability to be used with relatively cost-effective technologies, such as camera traps, make occupancy approaches effective for monitoring wildlife across large areas and evaluating nonlethal tool efficacy. Better development of effective tools and understanding of carnivore reactions to them will be critical endeavors as we strive to coexist with threatened and thriving carnivore populations throughout the world. 


\section{Acknowledgements}

Any use of trade, firm, or product names is for descriptive purposes only and does not imply endorsement by the U.S. Government. The findings and conclusions in this publication have not been formally disseminated by the U.S. Department of Agriculture and should not be construed to represent any agency determination or policy. We thank Z. Strong and E.M. Gese for insights that helped shape our study. T. Funabashi was instrumental in setting and checking wildlife cameras. The USGS Fort Collins Science Center mammal and plague crew, members of the Colorado State University Chapter of The Wildlife Society, and members of the Bailey Lab provided invaluable help installing, maintaining and deconstructing fladry exclosures. L. Pejchar, K. Wilkins and P. Dobesh provided cameras to support camera trap monitoring. GIS layers for all analyses and maps (Fig. 1) were obtained from the USFS, NPS and USDA NRCS Geospatial Data Gateway. L.M. Angeloni, D.E. Biggins and two anonymous reviewers provided valuable comments that greatly improved the quality and clarity of this paper. Funding for this project was supported by the Christine Stevens Wildlife Award from the Animal Welfare Institute, the National Resource Defense Council, and the US Department of Agriculture, National Wildlife Research Center.

\section{References}

Allen, B.L., Carmelito, E., Amos, M., Goullet, M.S., Allen, L.R., Speed, J., Gentle, M. \& Leung, L.-K.-P. (2016). Diet of dingoes and other wild dogs in peri-urban areas of northeastern Australia. Sci. Rep. 6, 1-8.

Andelt, W.F. \& Gipson, P.S. (1979). Home range, activity, and daily movements of coyotes. J. Wildl. Manage. 43, 944951.

Arnold, J., Humer, A., Heltai, M., Murariu, D., Spassov, N. \& Hacklaender, K. (2012). Current status and distribution of golden jackals Canis aureus in Europe. Mamm. Rev. 42, 111.

Arnold, T.W. (2010). Uninformative parameters and model selection using Akaike's Information Criterion. J. Wildl. Manage. 74, 1175-1178.

Biggins, D.E. (2000). Predation on black-footed ferrets (Mustela nigripes) and Siberian polecats (M. eversmannii): conservation and evolutionary implications (Doctoral dissertation). Fort Collins, CO: Colorado State University.

Biggins, D.E., Godbey, J.L., Livieri, T.M., Matchett, M.R. \& Bibles, B.D. (2006a). Postrelease movements and survival of adult and young black-footed ferrets. In Recover. blackfooted ferret Prog. Contin. challenges. Proc. Symp. status Black-footed Ferret its habitat: 191-200. Roelle, J.E., Miller, B.J., Godbey, J.L. \& Biggins, D.E. (Eds). Fort Collins, CO: United States Geological Survey (USGS).

Biggins, D.E., Lockhart, J.M. \& Godbey, J.L. (2006b). Evaluating habitat for black-footed ferrets: revision of an existing model. In Recover. black-footed ferret Prog. Contin. challenges. Proc. Symp. status Black-footed Ferret its habitat: 143-150. Roelle, J.E., Miller, B.J., Godbey, J.L. \& Biggins, D.E. (Eds). Fort Collins, CO: United States Geological Survey (USGS).

Biggins, D.E., Miller, B.J., Hanebury, L.R., Oakleaf, B., Farmer, A.H., Crete, R. \& Dood, A. (1993). A technique for evaluating black-footed ferret habitat. In Manag. prairie dog complexes reintroduction black-footed ferret: Vol. 13. 73-88. Oldemeye, J.L., Biggins, D.E. \& Miller, B.J. (Eds). Fort Collins, CO: U.S. Fish and Wildlife Service.

Blackwell, B.F., DeVault, T.L., Fernández-Juricic, E., Gese, E.M., Gilbert-Norton, L. \& Breck, S.W. (2016). No single solution: application of behavioural principles in mitigating human-wildlife conflict. Anim. Behav. 120, 245-254.

Breck, S.W., Biggins, D.E., Livieri, T.M., Matchett, M.R. \& Kopcso, V. (2006). Does predator management enhance survival of reintroduced black-footed ferrets. In Recover. black-footed ferret Prog. Contin. challenges. Proc. Symp. status Black-footed Ferret its habitat: 203-209. Roelle, J.E., Miller, B.J., Godbey, J.L. \& Biggins, D.E. (Eds). Fort Collins, CO: United States Geological Survey (USGS).

Breck, S.W., Poessel, S.A., Mahoney, P. \& Young, J.K. (2019). The intrepid urban coyote: a comparison of bold and exploratory behavior in coyotes from urban and rural environments. Sci. Rep. 9, 2104.

Burnham, K.P. \& Anderson, D.R. (2002). Model selection and multimodel inference: a practical information-theoretic approach. New York, NY: Springer-Veflag.

Butchko, P.H. (1990). Predator control for the protection of endangered species in California. In Proc. 14th Vertebr. Pest Conf: : 237-240. Davis, L.R. \& Marsh, R.E. (Eds). Sacramento, CA: University of California Davis.

Ceballos, G., Pacheco, J. \& List, R. (1999). Influence of prairie dogs (Cynomys ludovicianus) on habitat heterogeneity and mammalian diversity in Mexico. J. Arid Environ. 41, 161-172.

Davidson-Nelson, S.J. \& Gehring, T.M. (2010). Testing fladry as a nonlethal management tool for wolves and coyotes in Michigan. Hum.-Wildl. Interact. 4, 87-94.

Dormann, C.F., Elith, J., Bacher, S., Buchmann, C., Carl, G., Carré, G., Marquéz, J.R.G., Gruber, B., Lafourcade, B., Leitão, P.J., Münkemüller, T., Mcclean, C., Osborne, P.E., Reineking, B., Schröder, B., Skidmore, A.K., Zurell, D. \& Lautenbach, S. (2013). Collinearity: a review of methods to deal with it and a simulation study evaluating their performance. Ecography 36, 27-46.

Drouilly, M. \& O’Riain, M.J. (2019). Wildlife winners and losers of extensive small-livestock farming: a case study in the South African Karoo. Biodivers. Conserv. 28, 1493-1511.

Frid, A. \& Dill, L. (2002). Human-caused disturbance stimuli as a form of predation risk. Conserv. Ecol. 6, 11.

Gehring, T., Hawley, J., Davidson, S., Rossler, S., Cellar, A., Schultz, R., Wydeven, A. \& VerCauteren, K.C. (2006). Are Viable non-lethal management tools available for reducing wolf-human conflict? Preliminary results from field 
experiments. In Proc. Vertebr. Pest Conf: : 2-6. Timm, R.W. \& O'Brien, J.M. (Eds). Berkley, CA: University of California Davis.

Gehrt, S.D., Riley, S.P.D. \& Cypher, B.L. (2010). Urban carnivores: ecology, conflict, and conservation. Baltimore, MD: Johns Hopkins University Press.

Goodrich, J.M. \& Buskirk, S.W. (1995). Control of abundant native vertebrates for conservation of endangered species. Conserv. Biol. 9, 1357-1364.

Greggor, A.L., Berger-Tal, O. \& Blumstein, D.T. (2020). The rules of attraction: the necessary role of animal cognition in explaining conservation failures and successes. Annu. Rev. Ecol. Evol. Syst. 51, 483-503

Hody, A.W., Moreno, R., Meyer, N.F.V., Pacifici, K. \& Kays, R. (2019). Canid collision-expanding populations of coyotes (Canis latrans) and crab-eating foxes (Cerdocyon thous) meet up in Panama. J. Mammal. 100, 1819-1830.

Hody, J.W. \& Kays, R. (2018). Mapping the expansion of coyotes (Canis latrans) across North and Central America. ZooKeys 759, 81-97.

Iliopoulos, Y., Astaras, C., Lazarou, Y., Petridou, M., Kazantzidis, S. \& Waltert, M. (2019). Tools for coexistence: fladry corrals efficiently repel wild wolves (Canis lupus) from experimental baiting sites. Wildl. Res. 46, 484498.

Ivan, J.S. \& Newkirk, E.S. (2016). CPW Photo Warehouse: a custom database to facilitate archiving, identifying, summarizing and managing photo data collected from camera traps. Methods Ecol. Evol. 7, 499-504.

Kitchen, A.M., Gese, E.M. \& Schauster, E.R. (2000). Changes in coyote activity patterns due to reduced exposure to human persecution. Can. J. Zool. 78, 853-857.

Krueger, K. (1986). Feeding relationships among bison, pronghorn, and prairie dogs: an experimental analysis. Ecology 67, 760-770.

Lance, N.J., Breck, S.W., Sime, C., Callahan, P. \& Shivik, J.A. (2010). Biological, technical, and social aspects of applying electrified fladry for livestock protection from wolves (Canis lupus). Wildl. Res. 37, 708-714.

Lendrum, P.E., Crooks, K.R. \& Wittemyer, G. (2017). Changes in circadian activity patterns of a wildlife community post high-intensity energy development. $J$. Mammal. 98, 1265-1271.

Leroux, S.J. (2019). On the prevalence of uninformative parameters in statistical models applying model selection in applied ecology. PLoS One 14, e0206711.

Lewis, J.S., Bailey, L.L., Crooks, K.R., Logan, K.A., Alldredge, M.W. \& Vandewoude, S. (2015). The effects of urbanization on population density, occupancy, and detection probability of wild felids. Ecol. Appl. 25, 18801895.

Lima, S.L. \& Dill, L.M. (1990). Behavioral decisions made under the risk of predation: a review and prospectus. Can. J. Zool. 68, 619-640.
Livieri, T.M. \& Anderson, E.M. (2012). Black-footed ferret home ranges in Conata Basin, South Dakota. West. North Am. Nat. 72, 196-205.

MacKenzie, D.I., Nichols, J.D., Royle, J.A., Pollock, K.H., Bailey, L. \& Hines, J.E. (2017). Occupancy estimation and modeling: inferring patterns and dynamics of species occurrence. Amsterdam, Netherlands: Elsevier.

Matchett, M.R., Breck, S.W. \& Callon, J. (2013). Efficacy of electronet fencing for excluding coyotes: a case study for enhancing production of black-footed ferrets. Wildl. Soc. Bull. 37, 893-900.

Meek, P.D., Ballard, G.-A. \& Fleming, P.J.S. (2015). The pitfalls of wildlife camera trapping as a survey tool in Australia. Aust. Mammal. 37, 13-22.

Mettler, A.E. \& Shivik, J.A. (2007). Dominance and neophobia in coyote (Canis latrans) breeding pairs. Appl. Anim. Behav. Sci. 102, 85-94.

Much, R.M., Breck, S.W., Lance, N.J. \& Callahan, P. (2018). An ounce of prevention: quantifying the effects of nonlethal tools on wolf behavior. Appl. Anim. Behav. Sci. 203, 73-80.

Musiani, M., Gates, C.C., Mamo, C., Boitani, L., Volpi, G., Callaghan, C., Mattei, L., Visalberghi, E. \& Breck, S. (2003). Wolf depredation trends and the use of fladry barriers to protect livestock in western North America. Conserv. Biol. 17, 1538-1547.

Nattrass, N., Drouilly, M. \& O'riain, M.J. (2020). Learning from science and history about black-backed jackals (Canis mesomelas) and their conflict with sheep farmers in South Africa. Mamm. Rev. 50, 101-111.

Okarma, H. \& Jedrzejewski, W. (1997). Livetrapping wolves with nets. Wildl. Soc. Bull. 25, 78-82.

Prugh, L.R., Stoner, C.J., Epps, C.W., Bean, W.T., Ripple, W.J., Laliberte, A.S. \& Brashares, J.S. (2009). The rise of the mesopredator. Bioscience 59, 779-791.

Réale, D., Reader, S.M., Sol, D., McDougall, P.T. \& Dingemanse, N.J. (2007). Integrating animal temperament within ecology and evolution. Biol. Rev. 82, 291-318.

Ripple, W.J., Estes, J.A., Beschta, R.L., Wilmers, C.C., Ritchie, E.G., Hebblewhite, M., Berger, J., Elmhagen, B., Letnic, M., Nelson, M.P., Schmitz, O.J., Smith, D.W., Wallach, A.D. \& Wirsing, A.J. (2014). Status and ecological effects of the world's largest carnivores. Science 343, 1241484.

Royle, J.A., Nichols, J.D., Kéry, M. \& Kery, M. (2005). Modelling occurrence and abundance of species when detection is imperfect. Oikos 110, 353-359.

Royle, J.A., Nichols, J.D., Royle, A.J. \& Nichols, J.D. (2003). Estimating abundance from repeated presence-absence data or point counts. Ecology 84, 777-790.

Schroeder, G.M. (2007). Effects of coyotes and release site selection on survival and movement of translocated swift foxes in the Badlands ecosystem of South Dakota (Master thesis). Brookings, SD: South Dakota State University. 
Shaffer, T.L. \& Johnson, D.H. (2008). Ways of learning: observational studies versus experiments. J. Wildl. Manage. 72, 4-13.

Shivik, J.A. (2006). Tools for the edge: what's new for conserving carnivores. Bioscience 56, 253-259.

Sih, A., Bell, A. \& Johnson, J.C. (2004). Behavioral syndromes: an ecological and evolutionary overview. Trends Ecol. Evol. 19, 372-378.

Smith, G.C., McDonald, R.A. \& Wilkinson, D. (2012). Comparing badger (Meles meles) management strategies for reducing tuberculosis incidence in cattle. PLoS One 7, e39250.

Sollmann, R., Mohamed, A., Samejima, H. \& Wilting, A. (2013). Risky business or simple solution-relative abundance indices from camera-trapping. Biol. Conserv. 159, 405-412.

Trouwborst, A., Krofel, M. \& Linnell, J.D.C. (2015). Legal implications of range expansions in a terrestrial carnivore: the case of the golden jackal (Canis aureus) in Europe.

Biodivers. Conserv. 24, 2593-2610.

USDA APHIS. (2015a). Sheep and lamb predator and nonpredator death loss in the United States, 2015. United States Department of Agriculture, Animal and Plant Health Inspection Service report

USDA APHIS. (2015b). Cattle and calves death loss in the United States due to predator and nonpredator causes, 2015. United States Department of Agriculture, Animal and Plant Health Inspection Service report.

van Eeden, L.M., Eklund, A., Miller, J.R.B.B., Lopez-Bao, J.V., Chapron, G., Cejtin, M.R., Crowther, M.S., Dickman, C.R., Frank, J., Krofel, M., López-Bao, J.V., Chapron, G., Cejtin, M.R., Crowther, M.S., Dickman, C.R., Frank, J., Krofel, M., Macdonald, D.W., McManus, J., Meyer, T.K., Middleton, A.D., Newsome, T.M., Ripple, W.J., Ritchie, E.G., Schmitz, O.J., Stoner, K.J., Tourani, M. \& Treves, A.
(2018). Carnivore conservation needs evidence-based livestock protection. PLoS Biol. 16, e2005577.

White, G.C. \& Burnham, K.P. (1999). Program MARK: survival estimation from populations of marked animals. Bird Study 46, S120-S139.

Windell, R.M. (2019). Understanding and mitigating coyote predation on black-footed ferrets (Master thesis). Fort Collins, CO: Colorado State University.

Young, J.K., Draper, J. \& Breck, S. (2019a). Mind the gap: experimental tests to improve efficacy of fladry for nonlethal management of coyotes. Wildl. Soc. Bull. 43, 265271.

Young, J.K., Mahe, M. \& Breck, S. (2015). Evaluating behavioral syndromes in coyotes (Canis latrans). J. Ethol. 33, 137-144.

Young, J.K., Steuber, J., Few, A., Baca, A. \& Strong, Z. $(2019 b)$. When strange bedfellows go all in: a template for implementing non-lethal strategies aimed at reducing carnivore predation of livestock. Anim. Conserv. 22, 207209.

\section{Supporting information}

Additional supporting information may be found online in the Supporting Information section at the end of the article.

Appendix S1. Study area.

Appendix S2. Local prairie dog density.

Appendix S3. Detection models. Appendix S4. Coyote use models. Appendix S5. Avoidance models. Appendix S6. Attraction models.

Appendix S7. Activity models at control units. 